\title{
Las posibilidades del empleo de lactobacilos en la gastroenterología y la nutrición humana
}

\author{
Therapeutic potential of the use of \\ lactobacilli in gastroenterology \\ and human nutrition
}

\begin{abstract}
Lactobacilli are normal inhabitants of the human intestine. They are also present in maternal milk, where Lactobacillus reuteri was first described. This confirms that maternal milk transfers components of the maternal microbiota to the offspring. L. reuteri ATCC 55730 decreases the intensity and duration of infantile colic defined as episodes of strident crying for at least 3 hours, 3 times a week during 3 months. Its etiology is unknown but recent evidence shows that affected infants harbor less lactobacilli and more Bacteroides in their feces. In 2008 it was shown that this strain carries plasmidia that could transfer resistance to antibiotics. For this reason $L$. reuteri it was cured of these factors and this resulted in L. reuteri DSM 17938 which is devoid of them; tests in vitro, in laboratory animals and in humans demonstrated that both strains are equivalent. The effect of $L$. reuteri in infantile colic may be explained by its blocking at the level of the dorsal ganglia of the spinal chord of the transmission to the central nervous system of afferent pain stimuli. L. reuteri has effects on gastroesophageal reflux probably through the acceleration of gastric emptying and it decreases the incidence and severity of necrotizing enterocolitis. Other positive effects are related to chronic constipation and acute diarrhea. L. reuteri synthesizes a molecule with intense bactericidal activity, $\beta$-hidroxy propenal o reuterin from glycerol, which may explain some of its effects. Lactobacillus rhamnosus GG ATCC 53103 is probably the probiotic that has been studied the most and for a longer period. It shortens the duration and it decreases the number of evacuations in acute diarrhea as well as the duration and frequency of vomiting. It also induces improvements of antibiotic associated diarrhea and of upper respiratory infections. The positive effects of Lactobacillus GG may be due to the stimulation of innate and adaptive immunity and to the activation of macrophages and of NK lymphocytes. One of its effects refers the response its administration induces in infants with atopy/eccema. Some studies have demonstrated that the severity and extent of the lesions is decreased after Lactobacillus GG administration, that may persist for some years after its administration has been ended. Lactobacillus GG also exerts positive effects on conditions such as the irritable bowel syndrome through mechanisms that are not known with certainty.

Key words: Lactobacillus reuteri ATCC 53730; Lactobacillus reuteri DSM 17938; Lactobacillus rhamnosus GG ATCC 53103; reuterin, acute diarrhea.
\end{abstract}

Esta revisión analiza la evidencia existente acerca de dos de los probióticos más estudiados y utilizados y su relación con diversos aspectos de la salud humana; estos son: Lactobacillus reuteri ATCC 55730 y la cepa que lo reemplazó, Lactobacillus
Oscar Brunser T.

Representante en Chile, Nestlé Nutrition Institute Santiago, Chile

Dirigir la correspondencia a:

Oscar Brunser.

Profesor de Pediatría, Universidad de Chile Avda. Las Condes 11287 - $5^{\circ}$ Piso - Las Condes Santiago - Chile

E-mail: oscar.brunser@CL.nestle.com

Este trabajo fue recibido el 9 de Julio de 2013 y aceptado para ser publicado el 27 de Agosto de 2013.

reuteri DSM 17938, y Lactobacillus rhamnosus GG. Para subrayar algunos aspectos funcionales que se estiman de interés se hará mención a algunas otras cepas de lactobacilos que poseen capacidades que abren otras posibilidades de manejo 
de problemas de salud.

\section{Lactobacillus reuteri ATCC 55730 y \\ Lactobacillus reuteri DSM 17938}

Lactobacillus reuteri y el cólico infantil. Lactobacillus reuteri fue descubierto en la leche de una madre peruana y clasificado erróneamente como una capa de L. fermentum. En 1980 fue identificado como una especie distinta y se le asignó el nombre de reuteri en recuerdo a su descubridor, Gerhardt Reuter (1). L. reuteri se caracteriza por sintetizar una molécula con estructura química simple a partir del glicerol, el $\beta$-propionaldehido, que recibió el nombre de reuterina y posee potente actividad antibacteriana para numerosos enteropatógenos pero que no alteraría la microbiota residente del intestino.

Una de las características más interesantes de $L$. reuteri es su efecto sobre el cólico del lactante. Este cuadro fue definido en 1955 por Wessel como episodios de Ilanto excesivo, estridente, que se presentan al menos 3 horas durante 3 días a la semana y a lo menos por 3 meses (2). Para su manejo se ha recurrido a tratamientos que van desde manipulaciones de la columna vertebral, infusiones de menta, manzanilla, jenjibre, eneldo o asafétida, masajes, camas vibratorias, fórmulas lácteas parcial o extensamente hidrolizadas, supresión de alimentos de la dieta materna e interrupción de la lactancia. Los tratamientos que han producido algunos efectos positivos son la administración de gotas de whisky (desechado porque interferiría con el desarrollo del sistema nervioso central) o el bromuro de cimetropio (anticolinérgico). Esta variedad de tratamientos indica que ninguno de ellos ha tenido efectos evidentemente positivos. En las culturas occidentales el cólico afecta a 10 a $20 \%$ de los lactantes entre el primer y el tercer año de vida (3). En un estudio efectuado en la Isla de Wright, Hide y cols. observaron que en la mayoría de los casos el cólico ya había desaparecido alrededor del $5^{\circ}$ mes de vida aunque en algunos casos se prolongó hasta el año de edad (4).

En 2004, Savino y colaboradores publicaron los resultados de un estudio de la microbiota fecal de lactantes con cólico. En los lactantes con cólico había disminuciones significativas de los recuentos de lactobacilos $(p<0,03)$ en comparación con los controles y una tendencia al aumento de los anaerobios ( $p$ $<0,06)$. Los autores no adelantaron explicaciones para estos cambios pero consideraron que de alguna manera jugarían un papel en la patogenia de la sintomatología (5). Posteriormente, en un estudio prospectivo, randomizado en el que el grupo control recibió simeticona, los investigadores evaluaron el efecto de L. reuteri ATCC 55730 sobre la duración del Ilanto en lactantes con cólico. Un total de 41 lactantes que recibieron L. reuteri ATCC 55730 completó el período de observación así como 42 controles. Al inicio del estudio, la duración del Ilanto fue comparable en ambos grupos (197 minutros (margen: 180 - 276) para el grupo que recibió el probiótico vs 197 minutos (margen 180-279) ( $p=0.987$ ) para el grupo qye recibió simeticona. Al cabo de una semana la duración había disminuido a 159 minutos en el grupo que recibió I. reuteri y fue 177 minutos en el grupo control. A los 28 días los valores fueron 59 minutos y 145 minutos, respectivamente. Al día 28 los autores consideraron que 39 de los 41 lactantes que recibieron L. reuteri habían respondido al tratamiento, en comparación con sólo 3 pacientes (7\%) en el grupo que recibió simeticona. El efecto de $L$. reuteri fue independiente de los antecedentes de familia, concluyendo que el probiótico ejerció un efecto favorable sobre la duración del cólico y que representaba una herramienta terapéutica eficaz (5). Sin embargo, no tuvieron una explicación para el período inicial de latencia de su efecto, de aproximadamente 7 días (6).

En 2008 un análisis del genoma de L. reuteri ATCC 55730 determinó que era portador en su ADN cromosómico de un gen para una beta-lactamasa pero que, adicionalmente, albergaba dos plasmidios que incluían genes de resistencia a la tetraciclina y la lincomicina. En consecuencia, la cepa original fue "curada" de sus plasmidios, generando una cepa hija que recibió la denominación de L. reuteri DSM 17938, sin capacidad de transferir esta resistencia a antibióticos a otras bacterias de la microbiota. Pruebas adicionales in vitro confirmaron que las características de la cepa original de $L$. reuteri, incluso aquellas que la caracterizaban como un probiótico, se mantenían en la nueva cepa (7). Con todo, se hizo necesario evaluar si los efectos de esta nueva cepa eran diferentes de los de la cepa original respecto del cólico infantil. Savino y colaboradores (10) compararon sus propiedades en un estudio en doble ciego, randomizado y controlado con placebo practicado en lactantes con cólico amamantados en forma exclusiva: un grupo de 25 lactantes recibió $L$. reuteri DSM 17938 y otros 21 recibieron el placebo. La bacteria fue administrada una vez al día en 5 gotas de una suspensión oleosa y proporcionaban 108 UFC del microorganismo. Se midió la duración diaria del llanto, que fue $370 \pm 120$ minutos vs $300 \pm 150$ minutos en el día $0(p=0,127) ; 95 \pm 85$ minutos vs $185 \pm 140$ minutos en el día $7(p=0,082) ; 60 \pm 70$ minutos vs $150 \pm 145$ minutos en el día 14 y $35 \pm 85$ minutos vs 90 \pm 148 en el día 21 para quienes recibieron el probiótico o la fórmula control, respectivamente (valores expresados como promedio \pm rango intercuartil). Además se observó que los lactantes que recibían el probiótico no sólo lloraban menos tiempo sino que respondían a la administración del probiótico en números significativamente más elevados que los controles al placebo. Al día 21 se observó un aumento de los recuentos de lactobacilos y de Escherichia coli y un descenso de C. butyricum en las heces de los niños que recibieron $L$. reuteri; en estos lactantes se produjo también una disminución del amoníaco fecal $(p<0,001)$. No hubo diferencias en la ganancia de peso o la frecuencia de episodios de regurgitación o en el número de evacuaciones. Los autores postularon que $L$. reuteri DSM 17938 tenía efectos positivos sobre el cólico e inducía cambios de la microbiota colónica que consideraron asociados con la mejoría clínica. Nuevamente se observó un período de latencia entre el inicio de la administración del probiótico y la mejoría del Ilanto. Szajewska y colaboradores publicaron recientemente un estudio en el que administraron el mismo agente y en la misma dosis a 40 niños con cólicos, a quienes compararon con igual número de lactantes que sirvieron de controles (11). Los resultados exitosos fueron significativamente más frecuentes en los lactantes del grupo experimental, en quienes la duración del llanto se acortó. Los padres de los lactantes del grupo que recibió $L$. reuteri DSM 17938 tuvieron la percepción de que la intensidad del cólico fue menor y que la calidad de vida del grupo familiar mejoró. Este estudio demostró nuevamente que al séptimo día el efecto positivo se vuelve evidente en cuanto a la proporción de lactantes que experimentan disminuciones de los episodios de llanto y su duración. Los autores postulan que el uso de L. reuteri DSM 17938 debería ser discutido rutinariamente con los padres, especialmente si se tiene en cuenta que no existe un tratamiento efectivo para el cólico infantil y que los probióticos tienen un perfil de inocuidad satisfactorio. El mecanismo que causa la disminución del cólico no se conoce con precisión pero existe evidencia de que puede estar asociado 
con modificaciones del funcionamiento de las vías nerviosas que conducen estímulos generados a nivel intestinal hacia los núcleos del sistema nervioso central encargados de la percepción del dolor. Rousseaux y colaboradores demostraron que la administración oral de Lactobacillus acidophilus NCFM a ratones estimulaba la expresión de receptores opioides $m$ y endocanabinoides en la pared intestinal de los animales. Utilizando un modelo de hipersensibilidad visceral en ratones, mostraron que la administración de este probiótico aumentaba en forma dosis-dependiente el umbral de dolor asociado con la distensión del colon, de manera comparable con lo producido por la administración de dosis farmacológicas de morfina (12). Demostraron asimismo que $L$. reuteri actúa sobre las neuronas de los ganglios dorsales de la médula espinal y sobre las terminaciones nerviosas intraabdominales del vago y en los núcleos encargados de la percepción del dolor a nivel del sistema nervios central (13-16). La forma en que las bacterias presentes en el lumen generan mecanismos que bloquean la transmisión en los ganglios dorsales de la médula no se conocen con precisión.

Indrio y colaboradores observaron que $L$. reuteri ATCC 55730 ejercía efectos sobre la motilidad del estómago al ser administrado a prematuros en una fórmula láctea e inducía aumentos significativos de la velocidad de vaciamiento gástriCo, asociados con disminuciones de las regurgitaciones (17). Este grupo evaluó el efecto de la administración de 108 UFC de L. reuteri DSM 17938 en 5 gotas de un vehículo oleoso una vez al día por 30 días en 42 lactantes de 3 a 12 meses de edad que satisfacían los Criterios de Roma III para la definición de regurgitación y cuyo incremento de peso y talla era normal; los controles fueron 21 lactantes que recibieron solamente la base oleosa. Los parámetros de vaciamiento gástrico fueron determinados por ultrasonido después de ingerir la fórmula y se calculó la sección transversal del antro gástric: la disminución de este parámetro fue utilizada como un marcador del vaciamiento. Al final de la intervención el área del antro gástrico en ayunas fue significativamente menor en los lactantes que recibieron el $L$. reuteri y en elloa la velocidad de vaciamiento gástrico aumentó significativamente en comparación con los controles ( $p<0,01$ para ambas mediciones). El número diario de episodios de regurgitación se correlacionó con la disminución de la sección transversal del antro $(p=0.004)$. La comparación del grupo que recibió el lactobacilo con el grupo que recibió el placebo permitió demostrar una aceleración del vaciamiento gástrico, proponiendo que L. reuteri DSM 17938 modificaría el funcionamiento de las células intersticiales de Cajal y/o de las fibras musculares lisas gástricas (17).

\section{Otros efectos de L. reuteri ATCC 55730, DSM 17938}

y de otras cepas de lactobacilos

L. reuteri DSM 17938 fue utilizado en la prevención de la enterocolitis necrosante ECN en prematuros $\leq 1000 \mathrm{~g}$ de peso nacidos en Estados Unidos entre enero de 2004 y junio de 2009 en comparación con prematuros con características similares nacidos entre julio de 2009 y abril de 2011. En el primer grupo se evaluaron 232 prematuros y 79 en el segundo. La incidencia de ECN fue significativamente más baja en el grupo tratado con L. reuteri DSM 17938 (2/79; 2,5\% vs el grupo no tratado $(35 / 232 ; 15,1 \%)$. No hubo diferencias entre los grupos en relación con infecciones tardías por bacterias Gram-negativas o por hongos. De acuerdo con estos resultados es posible calcular que la administración de $L$. reuteri DSM 17938 previene 1 caso de ECN por cada 8 prematuros que recibieron preventivamente el probiótico (18).
L. reuteri DSM 17938 fue evaluado por Coccurullo y colaboradores en 44 lactantes con constipación crónica (19). Su edad promedio era 8,2 meses al ingresar al protocolo y de ellos 22 recibieron en 5 gotas/día de solución oleosa que proporcionaban $10^{8}$ UFC; al igual que en el estudio de Indrio (17) los controles sólo recibieron el vehículo. La constipación funcional fue definida de acuerdo con los criterios de Roma III (2 o menos evacuaciones/semana, pujos intensos, antecedentes de retención fecal excesiva con bolo fecal duro de gran diámetro y expulsión probablemente dolorosa, con presencia frecuente de una masa fecal en el recto). Durante el desarrollo del estudio la frecuencia semanal de evacuaciones aumentó progresivamente a las 2, 4 y 8 semanas en quienes recibieron el probiótico en comparación con el grupo que recibió el placebo. La consistencia fecal fue disminuyendo, aunque este último parámetro no fue diferente del grupo control; tampoco hubo diferencias respecto del llanto al defecar. Los autores estiman que este probiótico representaría una opción atractiva para el manejo de la constipación crónica de los lactantes. La administración de L. reuteri DSM 17938 estaría asociada con modificaciones de la motilidad del tubo digestivo, lo que para los autores probablemente se relacionaría con cambios funcionales de las células de Cajal. El probiótico actuaría mediante moléculas que actúan como mensajeros en los plexos nerviosos o indirectamente a través de mecanismos que modifican el funcionamiento de las células dendríticas. Probablemente los mecanismos que actúan sobre los plexos nerviosos de la pared intestinal explican también el efecto favorable de L. reuteri DSM 17938 en el dolor abdominal funcional en preescolares y escolares, en quienes se observaron disminuciones significativas de su intensidad aunque sin modificaciones de la frecuencia de los episodios. El efecto sobre la intensidad del dolor se prolongó en el tiempo después de interrumpir el probiótico (20) y el mecanismo podría ser similar al propuesto por Rousseaux (12) y por Storr y cols. (21). El efecto de L. reuteri DSM 17938 en el tratamiento de la diarrea aguda ha sido estudiado por diferentes grupos de investigadores. Según Wanke y Szajewska (22), L. reuteri DSM 17938 en una dosis de 108 UFC por día no previno la diarrea intrahospitalaria en niños de 1 a 48 meses de edad, incluyendo aquella causada por el rotavirus. Tampoco observaron efectos sobre manifestaciones secundarias tales como la aparición de nuevos episodios de diarrea, modificaciones de su duración o recurrencias después de 48 horas de evacuaciones normales; tampoco hubo modificaciones en riesgo de evoluciones a la cronicidad o la necesidad de rehidratación. Sin embargo, este estudio tiene algunos problemas de diseño. En el primero de estos estudios se estudió el efecto de L. reuteri DSM 17938 en la prevención de la diarrea nosocomial (22). Este es un cuadro conocido con diferentes denominaciones (infecciones asociadas con los procesos de cuidado de la salud, infecciones adquiridas en el hospital o de comienzo intrahospitalario) que se inicia 48 horas después de la admisión, cuya etiología más frecuente es el rotavirus y afecta al $27 \%$ de los niños hospitalizados. Su prevalencia exacta se desconoce porque es difícil obtener información de calidad al respecto. Se considera que L. rhamnosus GG y Bifidobacterium lactis ejercen efectos protectores, propiedad que también puede ejercer L. thermophilus (6-8). El estudio de Wanke y Szajewska fue prospectivo, randomizado, en doble ciego y controlado con placebo fue llevado a cabo en Varsovia, Polonia, entre 2009 y 2011 en niños de 1 a 48 meses de edad hospitalizados y cuyos diagnósticos excluían la diarrea aguda. Los criterios de exclusión fueron un episodio previo de diarrea en los 3 días 
anteriores a la admisión, cualquier otro síntoma sugerente de gastroenteritis, la presencia de sangre en las deposiciones y la alimentación con leche materna. L. reuteri DSM 17938 fue administrado en un dosis diaria única de 108 unidades formadoras de colonia (UFC) en 5 gotas de solución oleosa que fueron administradas bajo la supervisión de personal del estudio.

El principal resultado fue la incidencia de diarrea nosocomial, definida como $\geq 3$ deposiciones líquidas en 24 horas detectadas 72 horas después del ingreso al hospital. Los resultados secundarios fueron la detección de antígenos de rotavirus en las deposiciones, la incidencia de diarrea y su duración, la recurrencia de la sintomatología y la evolución prolongada (mayor de 14 días). Las muestras de deposiciones obtenidas al ingreso de cada uno de los niños fueron examinadas para detectar antígenos de rotavirus e identificar bacterias mediante métodos corrientes de cultivo. No parece que se hayan obtenido contemporáneamente muestras de los niños asintomáticos participantes durante la durante su hospitalización. De acuerdo con la literatura se podía esperar que 33\% de los niños desarrollaran un episodio de diarrea durante su hospitalización. Para obtener un resultado clínicamente significativo se estipuló que se esperaba una disminución de los episodios de diarrea de 50\% respecto del grupo placebo. Se calculó asimismo que el tamaño mínimo de la muestra debía ser de 88 pacientes y se adicionó un porcentaje de $20 \%$ para cubrir la deserción (dropout), con lo que el tamaño total de la muestra llegó a 106 sujetos, con 53 en cada grupo.

Al llevar a cabo la distribución de los participantes 54 niños conformaron el grupo que recibió el probiótico y 52 en el grupo que recibió el placebo. Las características demográficas de ambos grupos fueron comparables. Los resultados del estudio están resumidos en la tabla 1. Este estudio tiene como ventajas metodológicas el diseño experimental en doble ciego y controlado por placebo, el seguimiento durante toda la hospitalización y la obtención de una muestra de deposiciones en el momento de la hospitalización (muestra basal). Otra ventaja es que se consideró como episodios de origen nosocomial sólo a aquellos que fueron detectados después de 72 horas de la admisión en vez de las 48 horas aceptadas rutinariamente. La ausencia de diferencias en la incidencia de diarrea se mantuvo tanto si el intervalo inicial fue considerado de 48 o 72 horas. El efecto de la administración de antibióticos no fue tomado en consideración ya que el tratamiento de la diarrea es el mismo cualquiera sea su etiología y no debería incluir antibióticos. Por esta razón no se buscó específicamente la presencia de Clostridium difficile. La carencia de efecto de $L$. reuteri DSM 17938 fue atribuida por los autores a aspectos relacionados con el probiótico. En primer lugar, a la posibilidad de que este no sea el agente indicado para la prevención de esta patología, ya que el que resulte activo en el cólico no significa que necesariamente tenga que ser activo en procesos de diarrea. En segundo lugar, la dosis del probiótico puede haber sido insuficiente, aunque es la recomendada por el fabricante. Las dosis óptimas no han sido establecidas y es posible que una dosis más elevada tenga efectos positivos; es importante y asimismo probable que los resultados de la dosis de un probiótico no sea equivalente a la dosis activa de otro u otros microorganismos. Por ejemplo, en un estudio en el que L. rhamnosus GG mostró tener eficacia en la prevención de diarrea la dosis empleada fue de $10^{10}$ microorganismos al día (22).

Con todo, este estudio tiene problemas de diseño. En primer lugar, el rango de edad incluye lactantes menores y preescolares. Es un hecho conocido que después de los 2 años de edad, y sobre todo después de los 3 años de edad, la incidencia de diarrea disminuye porque la calidad de las respuestas del sistema inmune innato y adaptativo mejoran conjuntamente con el establecimiento de una microbiota residente más parecida a la de los adultos. De manera que un diseño más adecuado debería haber dividido y evaluado a la población en menores y mayores de 24 y/o 36 meses. En este nuevo diseño propuesto, el principal inconveniente es que queda estratificado por edad, por lo que para obtener un número adecuado de participantes que permitiría un análisis estadístico más preciso, habría sido necesario aumentar el número de sujetos participantes en cada uno de los grupos a más del doble. Una segunda objeción sería que los autores no parecen haber analizado la influencia de la duración de la hospitalización en la incidencia de diarrea. Mientras más prolongada es la hospitalización mayor es el riesgo de desarrollar episodios de esta enfermedad; por lo tanto, para determinar si L. reuteri DSM17938 ejerce efectos protectores habría sido

\section{TABLA 1}

Resultados primario y secundarios de L. reuteri DSM 17938 en la diarrea nosocomial.

\begin{tabular}{|c|c|c|c|c|}
\hline $\begin{array}{l}\text { Resultado } \\
(n=54)\end{array}$ & $\begin{array}{l}\text { Probiótico } \\
(\mathrm{n}=52)\end{array}$ & Placebo & RR (IC 95\%) & $\begin{array}{c}\text { Diferencia } \\
\text { promedio (IC 95\%) }\end{array}$ \\
\hline \multicolumn{5}{|l|}{ Primario n (\%) } \\
\hline Diarrea nosocomial & $18(33)$ & $16(31)$ & $1,06(0,7-1,5)$ & \\
\hline \multicolumn{5}{|l|}{ Secundarios } \\
\hline Rotavirus n(\%) & $10(18)$ & $9(17)$ & $1,04(0,6-1,6)$ & \\
\hline \multicolumn{5}{|l|}{ Diarrea n (\%) } \\
\hline \multicolumn{5}{|l|}{ Días con diarrea } \\
\hline Días \pm DS & $3,9 \pm 1,1$ & $4,1 \pm 1,1$ & & $0,2(-0,6$ a 0,2$)$ \\
\hline Diarrea recurrente & --- & --- & & \\
\hline Diarrea crónica & --- & --- & & \\
\hline Rehidratados & $6(11)$ & $19(19)$ & $0,7(0,3-1,2)$ & \\
\hline Duración de la hospitalización & $7,7 \pm 27$ & $7,3 \pm 2,7$ & & $0,41(-0,65$ a 1,45$)$ \\
\hline
\end{tabular}


interesante estratificar a los pacientes de acuerdo con la duración de su estadía en el hospital. Por este motivo, resultan más apropiados los seguimientos por períodos prolongados, como sucedió en el estudio de Saavedra y colaboradores, que demostró que L. rhamnosus GG protegía de la diarrea aguda (23). Otro factor que puede modular la calidad de los resultados es que L. reuteri DSM 17938 puede ejercer sus efectos protectores con una cierta latencia y que, por lo tanto, en el estudio en discusión haya habido participantes en quienes duración de la hospitalización no llegó a ser suficiente como para poner en evidencia los efectos protectores o estos fueron menores, especialmente si se tiene en cuenta la velocidad con que se instalan las respuestas inmunes adaptativas. Este es un aspecto importante si se considera que la duración promedio del período de hospitalización fue 7,7 $\pm 2,7$ días y 7,3 $\pm 2,7$ días en los grupos "Probiótico" y "Placebo", respectivamente (22).

Francavilla y colaboradores observaron que $L$. reuteri DSM 17938, administrado como adjunto a la rehidratación de lactantes en una dosis de 4 × 108 UFC/día disminuyó la duración de la diarrea en aproximadamente un día, con mayor impacto en el segundo y tercer días de su administración y redujo la frecuencia de recaídas (24). Estos resultados coinciden con los obtenidos por Shornikova en Estonia (25); es posible que el efecto positivo sobre la diarrea aguda sea explicado por mecanismos, propios de este probiótico, entre ellos la capacidad de sintetizar reuterina (26). L. reuteri DSM 17938 ha demostrado ser efectivo en la prevención de la diarrea que se presenta en el curso del tratamiento con antibióticos para erradicar el $H$. pylori (27).

Los antecedentes antes mencionados apoyan la idea que desde el punto de vista funcional $L$. reuteri, ATCC 55730 y $L$. reuteri DSM 17938, funcionan de manera equivalente en las patologías estudiadas. Es importante tener en cuenta estos hallazgos ya que otras cepas de la misma especie microbiana poseen efectos totalmente diferentes. Por ejemplo, Lactobacillus reuteri NCIMB 30242 hace descender los niveles de colesterol sérico de adultos hipercolesterolémicos porque posee actividad de hidrolasa de las sales biliares. (28-32). Nuevamente este sería un efecto cepa-específico.

Existe una amplia bibliografía respecto del efecto de $L$. reuteri en la diarrea aguda. Los resultados con varias cepas de $L$. reuteri en la diarrea aguda son variables; algunas publicaciones indican que es efectivo en el control de esta enfermedad mientras que según otros no tendría efecto. En 1997 Shornikova y cols. publicaron estudios que demostraron que $L$. reuteri acorta la duración de la diarrea en forma dosis-dependiente, de manera que su duración fue 2,5 \pm 1,5 días en el grupo que recibió placebo ( 25 niños), 1,9 0,9 días en quienes recibieron $10^{7}$ UFC una vez al día por 5 días (20 niños) y 1,5 $\pm 1,1$ días en quienes recibieron $10^{10}$ UFC por igual período de tiempo (33). Los coprocultivos demostraron que se alcanzó un nivel satisfactorio de colonización del tracto gastrointestinal, con recuentos de $4,5 \pm 2,0 \log 10 \mathrm{UFC} / \mathrm{g}$ en quienes recibieron los recuentos bajos de L. reuteri y 6,1 $\pm 1,2 \log 10 \mathrm{UFC/g}$ en quienes recibieron la dosis más elevada y de sólo $2,8 \pm 1,6$ log10 UFC/g en los que sirvieron de controles, . De los pacientes incorporados a estos estudios, 75\% estaba afectado por rotavirus en el primer estudio mientras que estaba presente en todos los del segundo estudio (33).

Publicaciones posteriores, algunas de ellas efectuadas con L. reuteri ATCC 55730 y otras con la cepa DSM 17938, demostraron efectos beneficiosos de mayor o menor intensidad en episodios de diarrea de diversa etiología, principalmente en aquella causada por rotavirus (34-37). L. reuteri ATCC 55730 ejerció efectos preventivos sobre la diarrea en pacientes colonizados por H. pylori y tratados con levofloxacino; al mismo tiempo la tasa de erradicación aumentó significativamente ( $p$ $<0,05)(38)$. En el estudio de Wanke y Szajewska (39) en el que indicaron que L. reuteri DSM 17938 no previno la aparición de episodios de diarrea intrahospitalaria, se ensayó una dosis diaria de L reuteri DSM 17938 (10 UFC) pero no se puede descartar que dosis más altas ejerzan efectos preventivos. Contrastando con este resultado, otros tres estudios demostraron que Lactobacillus GG ejerce efectos preventivos en la diarrea intrahospitalaria (42) al igual que dos cepas diferentes de $L$. rhamnosus, 19070 y DSM 12246 (40, 41). Estos resultados refuerzan el concepto, expresado anteriormente, que los efectos de los probióticos tienen especificidad respecto de especie y cepa y que otro aspecto importante es la utilización de dosis óptimas.

En marzo de 2012 L. reuteri DSM 17938 recibió la calificación GRAS de parte de la Food and Drug Administration (FDA) de los Estados Unidos.

\section{Lactobacillus rhamnosus GG (ATCC 53103)}

Lactobacillus GG es una cepa aislada en 1983 del tracto gastrointestinal de un individuo sano; fue descrita por Gorbach y Goldin (de cuyas iniciales se originó la denominación) y fue patentada en 1985 (42). Está cepa está registrada en la American Type Cell Collection (ATCC) con el número 53103. Lactobacillus GG fue clasificado originalmente como L. acidophilus, posteriormente como $L$. casei y finalmente como $L$. rhamnosus cuando se describió la totalidad su genoma. Goldin y colaboradores demostraron que Lactobacillus GG sobrevivía el paso a lo largo del tubo digestivo (42), persistía por 4 días en las heces de $87 \%$ de los voluntarios que lo habían ingerido y era detectable en $33 \%$ de ellos hasta los 7 días; además inducía descensos de la $\beta$-glucuronidasa fecal (42). Resultados similares en cuanto a su persistencia de en el intestino humano fueron observados (43-45).

Lactobacillus GG en la diarrea aguda. En 1995 Majamaa y colaboradores observaron que la administración de Lactobacillus GG acortaba en niños en casi 24 horas la duración de la diarrea asociada con la presencia de rotavirus $(1,8 \pm 0,8$ días) en comparación con lo observado cuando se administró L. casei ( $2,8 \pm 1,2$ días) y 2,6 1,2 días cuando se administró una mezcla de Streptococcus thermophilus y L. delbrückii subsp bulgaricus como control. Estos resultados se asociaron con aumentos de IgA secretoria específica para rotavirus en las heces y en el suero de los convalecientes (46). Estudios posteriores confirmaron estos resultados en la diarrea por rotavirus aunque el efecto sobre la diarrea de etiología bacteriana es variable (47-53).

Un estudio efectuado en Kolcatta, India, en menores de 36 meses con diarrea definida como > 3 evacuaciones diarias no reveló diferencias en su evolución clínica entre quienes recibieron Lactobacillus GG y el grupo control (microcelulosa), excepto en que en el grupo que recibió el probiótico se observó una disminución de los vómitos. Sin embargo, aunque el número de niños estudiados por protocolo en este estudio es bastante grande (105 niños por grupo), ambos grupos eran heterogéneos en cuanto a su alimentación, que fueron amamantados exclusiva o parcial o alimentados con fórmulas y además presentaban grados variables de desnutrición, principalmente moderada, con una alta proporción de síntomas de malabsorción de lactosa. Los lactantes con diarrea por rotavirus recuperaron su estado nutricional previo al episodio de diarrea con mayor lentitud (54). 
Dos estudios australianos comunicaron no haber observado efectos positivos de Lactobacillus GG sobre la evolución de la diarrea. El primero (58) fue llevado a cabo en adultos gravemente enfermos que recibían alimentación por sonda gástrica y recibieron dos veces al día una preparación (Floratil, Conagra, USA) que contenía $10^{10}$ UFC de Lactobacillus GG y $280 \mathrm{mg}$ de inulina en una cápsula de gelatina. En el diseño en doble ciego el grupo control recibía la cápsula con inulina sin el probiótico (55). No se observaron diferencias significativas entre ambos grupos en cuanto a la duración o la intensidad de la diarrea; incluso hubo cierta tendencia a una mayor duración de los episodios y del número de evacuaciones en el grupo experimental, pero sin llegar a tener significancia estadística. Sin embargo, este estudio origina objeciones acerca de su diseño por la gravedad de los pacientes, el intenso compromiso del estado nutricional de algunos de ellos, el tratamiento simultáneo de C. diffícile con metronidazol, el uso de aspartato de magnesio y de una fórmula alimenticia con alta osmolaridad. Además, no se efectuaron estudios para aclarar la intervención de agentes virales o bacterianos en la etiología de la diarrea. En el segundo estudio, Ritchie y colaboradores (56) controlaron clínicamente a niños aborígenes australianos de 4 meses a 2 años de edad que presentaban diarrea y a quienes, en un estudio en doble ciego, randomizado y con grupo control, se les administró disuelto en agua destilada 3 veces al día el contenido de cápsulas con $5 \times 10^{9}$ UFC de Lactobacillus GG o un placebo con igual apariencia. Los niños recibieron además hidratación oral o parenteral de acuerdo con su estado clínico, $20 \mathrm{mg}$ de zinc y una dosis única de 50.000 o 100.000 unidades de vitamina A. La presencia de malabsorción intestinal fue evaluada mediante la medición de ${ }^{13} \mathrm{CO} 2$ en el aire espirado después de administrar ${ }^{13} \mathrm{C}$-sacarosa. De los participantes, cuya edad promedio era 9 meses aproximadamente, el $70 \%$ estaba amamantado. En algunos pacientes los episodios de diarrea estaban asociados con la presencia de rotavirus, enteropatógenos o parásitos (54 \% en el grupo experimental y 38 $\%$ en el grupo control) y algunos presentaban comorbilidades (pioderma, neumopatías, infecciones del tracto urinario u otitis). No se detectaron diferencias significativas en la excreción de ${ }^{13} \mathrm{CO} 2$ durante los días primero y cuarto aunque hubo cierto grado, no significativo, de mejoría de estos valores. Los probióticos no disminuyeron la duración de la diarrea pero el grupo que recibió el probiótico tuvo menos evacuaciones durante el día 2 del tratamiento, diferencia que desapareció en los días siguientes (56). Como el estudio anterior (55), este estudio tiene problemas de diseño tales como tamaño muestral inadecuado, heterogeneidad clínica de los pacientes y la administración de zinc y vitamina $A$, que pueden haber interferido con las respuestas a los probióticos (56). En cuanto a la función intestinal, en vez de la prueba con $1{ }^{3} \mathrm{C}$-sacarosa hubiera sido preferible realizar mediciones de la permeabilidad del tubo digestivo (sacarosa, lactulosa/manitol o sucralosa).

Un tercer estudio realizado en Perú tampoco demostró efectos clínicos positivos en la evolución de la diarrea asociados con la administración de Lactobacillus GG aguda (57). Este estudio adolece de cuatro problemas: los niños admitidos al grupo que recibió Lactobacillus GG probablemente eran casos más graves ya que en un mayor porcentaje (60 \%) sufría de deshidratación más intensa en comparación con el grupo control (40\%). La administración del probiótico fue tardía ya que para obtener efecto se aconseja su administración precoz; la prevalencia de casos de diarrea por rotavirus fue más elevada en el grupo control (39\% vs $24 \%$; $p<0,05$ ). Finalmente, casi la mitad de ambos grupos evidenció durante el estudio síntomas y signos de fermentación intestinal (evidenciada por el descenso del pH fecal), lo que es un índice de agravamiento del daño de la mucosa intestinal con aparición de intolerancia a los hidratos de carbono y especialmente, a la lactosa de la fórmula usada para alimentarlos (57).

Diversos autores sostienen con mayor o menor énfasis que Lactobacillus GG protege de la diarrea aguda, incluyendo de aquella nosocomial. Guandalini mantiene que muchos estudios "...muestran consistentemente un beneficio estadísticamente significativo y beneficios clínicos moderados con el uso de unas pocas cepas de probióticos claramente identificados principalmente Lactobacillus GG y Saccharomyces boulardii pero también $L$. reuteri- en el tratamiento de la diarrea líquida, primariamente en aquella causada por rotavirus, en lactantes y preescolares de países desarrollados" (58). Szajewska y colaboradores mostraron en un meta-análisis que Lactobacillus GG disminuye significativamente la duración de la diarrea aguda, especialmente de aquella causada por rotavirus y en menor grado en los casos sin etiología demostrada sin afectar, sin embargo, el número de evacuaciones emitidas. El probiótico también disminuye los vómitos en el segundo día del tratamiento y la duración de las hospitalizaciones. Szajewska y colaboradores concluyen que el uso de Lactobacillus GG está asociado con beneficios clínicos en el tratamiento de la diarrea aguda en niños de los países desarrollados (49). PiescikLech y colaboradores mostraron que la adición de smectita al tratamiento de la diarrea aguda con solución de rehidratacion oral + Lactobacillus GG no aumentaba su eficiencia. Sin embargo, pese al resultado positivo para Lactobacillus GG, en este estudio faltan dos controles: un grupo que debería recibir solamente smectita y otro que no debería recibir ningún tratamiento adicional, excepto rehidratación y alimentación $y$, sólo si fuese pertinente, antibióticos. El problema con este nuevo diseño propuesto es que para alcanzar una potencia estadística adecuada el número de pacientes que se requiere enrolar se multiplica exponencialmente (59).

Lactobacillus rhamnosus GG y diarrea asociada con el uso de antibióticos. Lactobacillus rhamnosus GG es efectivo en el tratamiento de la diarrea asociada con los tratamientos con antibióticos. Estos resultados son respaldados por varias publicaciones que apoyan la idea de que este probiótico debería ser la primera elección en el tratamiento de este cuadro y que incluso tendría efectos preventivos (59-63).

Lactobacillus rhamnosus GG en infecciones respiratorias. Una de las causas frecuentes de ausentismo a los jardines infantiles son las infecciones respiratorias, que afectan $2-3$ veces más a estos niños que a aquellos que permanecen en su hogar. El mayor número de episodios resulta en aumentos de los gastos no sólo para el sistema educacional sino porque intervienen otros factores tales como el ausentismo materno al trabajo, consultas al sistema de salud, adquisición de medicinas, entre otras (64).

Hattaka y colaboradores evaluaron el efecto de la administración de una fórmula láctea con Lactobacillus GG sobre el número de días con síntomas respiratorios y gastrointestinales en 571 niños de 1 a 6 años de edad que concurrían a 18 guarderías infantiles de Helsinki, Finlandia. Los niños que recibieron el probiótico tuvieron menos días de ausencia durante los 7 meses de observación y una disminución del $17 \%$ de las infecciones respiratorias y sus complicaciones junto con un $19 \%$ de descenso del uso de antibióticos (65).

Recientemente fueron publicados dos estudios acerca de los efectos de Lactobacillus GG en infecciones respiratorias en niños que concurrían a guarderías infantiles o estaban 
hospitalizados en Zagreb, Croacia. En ambos casos los niños recibieron $100 \mathrm{ml}$ de una fórmula que contenía $10^{9}$ UFC de Lactobacillus GG o, la misma fórmula sin este agente como control. Los niños que concurrían a jardines infantiles recibieron este producto durante 3 meses; aquellos hospitalizados la recibieron mientras duró su estadía en el hospital. En los jardines infantiles se observó una disminución significativa del riesgo de infecciones respiratorias [RR 0,63; CI 95\% 051 - 0,79; número necesario para tratar 5 (rango 3-8 días)]; no se detectaron efectos preventivos sobre las infecciones gastrointestinales. La frecuencia de episodios de diarrea con duraciones mayores de 3 días de los fue menor en quienes recibieron Lactobacillus GG pero no hubo diferencias respecto de la incidencia de infecciones broncopulmonares. Tampoco hubo diferencias en la incidencia de vómitos o diarrea al comparar los niños del grupo experimental con sus controles. En los niños que recibieron el placebo, el número de días con síntomas respiratorios fue mayor $(p<0,001)$ y su riesgo de infecciones del tracto respiratorio fue 2,88 veces mayor en comparación con quienes recibieron Lactobacillus GG. En los niños hospitalizados los resultados fueron comparables pero con algunas diferencias ya que sufrieron menos infecciones gastrointestinales y del tracto respiratorio, menos episodios de diarrea y de menor duración, aunque la duración de las hospitalizaciones no se modificó. Los autores manifiestan que Lactobacillus GG puede ser útil para disminuir el riesgo de enfermedades respiratorias en los niños que concurren a guarderías infantiles o en quienes están expuestos al riesgo de infecciones nosocomiales $(66,67)$.

Otra publicación evaluó la sintomatología respiratoria de niños de 2 a 6 años de edad que concurrían a guarderías infantiles en Finlandia y confirma que en quienes completaron un seguimiento de 28 semanas se observó una disminución del número de días con al menos un síntoma respiratorio (Lactobacillus GG: 4,71 días/mes (CI $95 \%$ 4,52 -4,90) vs 5,67 días/ mes en el grupo placebo (IRR 0,83: IC $95 \% 0,78-0,88$ : $p<$ $0,01)(68)$. Otras publicaciones también muestran resultados que concuerdan con la información precedente.

Respecto de los mecanismos que explicarían los efectos positivos de Lactobacillus GG se puede especular que estos resultados extradigestivos se deberían a la estimulación de la inmunidad tanto innata como adquirida, y a linfocitos B y $\mathrm{T}$ que migran desde el tubo digestivo y se localizan en el aparato respiratorio produciendo IgA específica e IgG a nivel local. En estudios in vitro se ha demostrado que Lactobacillus GG activa macrófagos y células natural killer además de procesos antiinflamatorios y de reparación. Por otra parte, LactobacillusGG sintetiza p40, una proteína soluble que mediante la síntesis del receptor para el factor de crecimiento epitelial (EGFR, epithelial growth factor receptor) previene la apoptosis de las células epiteliales intestinales inducida por citoquinas. En modelos animales la proteína p40 previene las alteraciones de la función de barrera del epitelio intestinal $(69,70)$.

Lactobacillus GG y manifestaciones de alergia, eccema y atopia. Uno de los fenómenos más notables observados en los decenios recientes es el aumento de las manifestaciones alérgicas en todas sus formas y ámbitos geográficos (7174). Este fenómeno se observa también en Chile, aunque las cifras de que se dispone son menos precisas. Las causas de este aumento no se conocen una de las explicaciones se fundamenta en los postulados de la hipótesis de la higiene (75). Aproximadamente $10 \%$ de la población menor de 10 años puede estar afectada por fenómenos de tipo alérgico $(76,77)$. Como se demostró que los probióticos modulaban el funcionamiento del sistema inmune, que está en desarrollo durante la gestación e incluso después del parto, algunas de las primeras investigaciones en este campo exploraron este enfoque. Kalliomäki e Isolauri (78) presentaron evidencia de este efecto de los probióticos, que podría ser explicado por disminuciones de los fenómenos inflamatorios en la mucosa intestinal con reforzamiento de la función de barrera. Una serie de tres artículos describieron el seguimiento por varios años de una cohorte de niños finlandeses cuyas sus madres tenían antecedentes de atopia al igual que otros componentes del grupo familiar. Las madres recibieron una cápsula que contenía $1 \times 10^{9}$ UFC de Lactobacillus GG o un placebo con igual aspecto dos veces al día en las 2 a 4 semanas previas al parto. Después del parto las madres que amamantaban podían seguir ingiriendo el probiótico pero si no amamantaban el lactante recibía el contenido de las cápsulas disuelto en agua; en ambos casos los recuentos de Lactobacillus GG en las heces de los lactantes fueron similares. Los niños fueron examinados a los $3,6,12,18$ y 24 meses, esta última en la que se evaluaron los resultados del tratamiento. La evolución de las manifestaciones cutáneas de atopia, principalmente el eccema, se efectuó mediante el índice SCORAD. Se practicó a los niños un prick test cutáneo a los 6, 12 y 24 meses además de mediciones de la IgE total y específica para la leche de vaca en la sangre del cordón umbilical y a los 3, 12 y 24 meses. Al nacer los lactantes de ambos grupos fueron comparables en sus características antropométricas y de laboratorio. A los 2 años 46/132 niños (35\%) tenían manifestaciones de eccema y 6 eran asmáticos. Se les practicó prick tests para diversos alérgenos, los que resultaron positivos con más frecuencia en los niños con eccema. En los niños que recibieron el probiótico, la frecuencia de eccema atópico fue la mitad que en los niños del grupo control, aunque la extensión de las lesiones era semejante. El efecto preventivo era independiente de la forma en que el Lactobacillus GG fue administrado. Las concentraciones de IgE total y los aumentos de IgE específica fueron comparables en ambos grupos. Los autores postularon que la microbiota intestinal jugaría un papel importante en modulación de la inmunidad tanto a nivel intestinal como sistémico y que los probióticos podrían participar en este mecanismo, lo que en el caso de Lactobacillus GG se manifestaría por la disminución de la atopia cutánea. Estos pacientes fueron evaluados a los 4 y 7 años de evolución del estudio por los mismos autores $(79,80)$. A los 4 años se diagnosticó eccema en 14/53 niños que habían recibido Lactobacillus GG en contraste con 25/54 en el grupo control (RR 0,57; IC $95 \%$ : 0,33-0,97). No hubo diferencias significativas en los demás parámetros estudiados (óxido nitroso en el aire espirado, prick tests, mediciones de IgE) (82). A los 7 años, los resultados expresados como curvas de Kaplan-Meier en que se comparó la presencia de fenómenos de atopia demostraron que el riesgo acumulado de desarrollar eccema era menor en el grupo tratado con Lactobacillus GG (42\% vs 66,1\%; RR 0,64; IC $95 \%$ 0,45 - 0, 92); el análisis de regresión de Cox demostró que el riesgo de desarrollar eccema también era significativamente menor en quienes recibieron el probiótico [relación de probabilidad (odds ratio) 0,58; IC $95 \% 0,35-0,94 ; p=0,027]$. Los autores no proporcionaron una explicación para estos resultados ya que los otros parámetros estudiados en esta cohorte son comparables en ambos grupos. Se sabe que en los niños con eccema hay aumentos del transporte de antígenos a través del epitelio intestinal y que hay alteraciones de la microbiota intestinal residente, pero la importancia relativa de estos factores es desconocida (80). Estos estudios han provocado intensas discusiones, sobre 
todo en lo que respecta a la persistencia de la disminución del eccema durante un período tan prolongado después de terminada la administración del probiótico.

Un aspecto importante que ha sido necesario precisar es si el efecto positivo del probiótico en las manifestaciones de alergia requiere que el agente esté viable. En un estudio de Kirjavainen y asociados, la administración de Lactobacillus GG inactivado por calor a lactantes con eccema se asoció con diarrea y otras molestias digestivas en 38,4\% del grupo, incluso aunque el SCORAD y las molestias subjetivas asociadas con el eccema mejoraron. La explicación propuesta por los autores es que estos lactantes albergaban en su microbiota colónica números aumentados de clostridios y bacteroides los que en presencia de los lactobacilos inactivados secretaron toxinas diarreicas. Los lactobacilos viables secretan al lumen intestinal enzimas capaces de neutralizar los efectos de estas toxinas, capacidad que está ausente en las bacterias no viables. Otra posibilidad sería que durante el calentamiento los lactobacilos expresan proteínas de shock térmico que modifican sus capacidades inmunoestimuladoras, de forma tal que en vez de ejercer efectos antiinflamatorios tendrían efectos opuestos. Es posible que los probióticos viables estimulen también la producción de interferón (IFN)-g por los linfocitos y otros mononucleares presentes en la mucosa intestinal (81). Manifestaciones similares fueron observadas también en lactantes de 1,5 a 12 meses de edad que sufrían de dermatitis alérgica asociada con la leche de vaca, quienes recibieron Lactobacillus GG solo o asociado con otros probióticos. Algunos lactantes tenían niveles elevados de IgE específica y de IFN-g mientras que en otros la manifestación de atopia no estaba asociada con niveles elevados de IgE ni de IFN-g. Se supone que en estos últimos casos el cuadro alérgico sería causado por mecanismos celulares ya que en los pacientes había además una disminución de la IL-4 circulante, que contrarresta los efectos del IFN-g. Los probióticos, entre ellos Lactobacillus GG, actuarían como contrareguladores del perfil $\mathrm{TH}-2$ de de los lactantes alérgicos y desviarían dicho perfil TH-2, hacia el perfil TH-1, considerado más maduro, en un proceso que normalmente evoluciona entre los 6 y los 18 meses de vida. De manera que a través de modulaciones de la composición de la microbiota intestinal y de la estimulación de los patrones de las respuestas inmunes los probióticos ejercerían efectos positivos sobre la evolución de la alergia a proteínas de la leche de vaca (82). En las heces de pacientes con dermatitis atópica/eccema que recibieron Lactobacillus GG, ya sea aislado o como parte de una mezcla de cuatro probióticos se detectaron descensos de algunos marcadores de inflamación intestinal (83). Al revisar la literatura reciente sobre este tema se observa que mientras que en un número de publicaciones se afirma que Lactobacillus GG ejerce efectos positivos sobre la evolución de los fenómenos alérgicos, para otros autores dichos efectos no son tan evidentes o no existen; en ningún estudio se describen efectos adversos. Bischoff y Crowe recomiendan el uso de Lactobacillus GG para prevenir y tratar las alergias a alimentos (84 en tanto que Viljanen y colaboradores sugieren que el probiótico puede aliviar el eccema atópico/dermatitis en lactantes en quienes su sintomatología está asociada con niveles aumentados de IgE específica circulante pero no en aquellos en quienes estos niveles no están aumentados. Los autores creen que este efecto de Lactobacillus GG obedece a que induce un proceso inflamatorio de baja intensidad que se manifiesta a través de aumentos de la proteína C-reactiva, la IL-6 y la E-selectina. Este probiótico, incorporado a la mezcla de cuatro microorganismos denominada MIX inducía aumentos de la citoquina IL-10, que ejerce efectos antiinflamatorios $(85,86)$. En lactantes alérgicos con hematoquecia que recibieron Lactobacillus GG, los niveles de calprotectina fecal, considerablemente elevados al inicio del tratamiento, descendieron hasta $50 \%$ después de las 4 semanas de tratamiento. Cuando Lactobacillus GG fue incorporado a una fórmula con su proteína extensamente hidrolizada (Nutramigen LGG, Mead Johnson, Ind., USA) el descenso fue más considerable y las 4 semanas ningún lactante (12/12) evidenciaba sangrado rectal; de los lactantes que recibieron la fórmula extensamente hidrolizada control sin Lactobacillus GG, 5/14 continuaron con sangrado $(p=0,002)$ (87). Otro estudio confirmó estos resultados ya que en lactantes de 1 a 12 meses que fueron tratados con Nutramigen la adición de Lactobacillus GG aceleró la aparición de tolerancia para las proteínas de leche de vaca, la que persistió por a lo menos seis meses. Los autores atribuyeron la aparición y la persistencia de dicha tolerancia a la estimulación de la síntesis de IL-4, IL-5, IL-10 e IFN-g, así como de TGF-b y TNF-a en los lactantes en quienes el proceso alérgico era mediado tanto por IgE como por mecanismos celulares sin participación de la IgE. Estos factores contribuyen a regular hacia la disminución los fenómenos inflamatorios propios de la alergia (88). Nuevamente, se trata de un proceso cepa-específico porque otras cepas de lactobacilos administrados en dosis comparables no produjeron resultados comparables (89). Una investigación efectuada en Europa con los mismos probióticos y la misma fórmula láctea con proteína estaba extensamente hidrolizada, confirmó los resultados anteriores (90).

Autores japoneses demostraron en adultos cuya edad promedio era 50 años aproximadamente que el consumo de una leche fermentada que contenía Lactobacillus GG asociado con tres probióticos disminuía después de 9 semanas sus síntomas de obstrucción nasal y la necesidad de fármacos para aliviarlos, en comparación con quienes recibieron placebo. Además, Lactobacilluss GG inhibía in vitro la producción de IL-4 e IL-5 estimulada por fitohemaglutinina en sus mononucleares sanguíneos. Los autores atribuyeron estos efectos a un proceso de regulación hacia la disminución del perfil de reacción TH-2 $(91,92)$. Los mismos autores demostraron que los sujetos con reacción al polen del cedro japonés tenían una menor diversidad de la población de bifidobacterias en su microbiota colónica y que dicha diversidad aumentaba al administrar los probióticos. En su opinión las bifidobacterias de la microbiota fecal pueden llegar a constituir un objetivo de futuros tratamientos $(91,92)$.

Existen publicaciones que no muestran efectos favorables de Lactobacillus GG en la dermatitis atópica de la infancia. En un diseño en doble ciego, controlado con placebo y con confrontación con el alérgeno (iniciales en inglés DBPCFC) Brower y colaboradores administraron una leche extensamente hidrolizada (Nutrilón Pepti Lactobacillus GG o Nutrilón Pepti L. rhamnosus, Nutricia, Cluijk, Holanda) a lactantes con eccema por alergia a proteínas de la leche de vaca. Se evaluó su índice SCORAD y se midieron parámetros de inflamación (a-1-antitripsina en deposiciones y proteína $X$ de eosinófilos en la orina, además de IL-4, IL-5 e IFN-g en su sangre). Se estudiaron 50 y de ellos sólo 14 mostraron una mejoría de su SCORAD de poca intensidad. Ninguno de los parámetros de sensibilización alérgica o de inflamación mostró disminuciones estadísticamente significativas sólo tendencias (93). En un estudio cuyo diseño guarda un estrecho parecido con los de Kalliomäki $(78,79)$ no se observaron beneficios en el SCORAD como resultado de la administración de Lactobacillus GG a la madre durante el embarazo y al lactante durante el postparto; 
más aún, se detectó un aumento de las recurrencias de bronquitis con sibilancias respiratorias. Los autores no recomiendan el uso de Lactobacillus GG en estos casos $(93,94)$. En otro estudio, los efectos de la administración del probiótico fueron evaluados en 76 madres embarazadas quienes recibieron 1,8 $\mathrm{x}$ $10^{10}$ UFC de Lactobacillus GG o un placebo desde la semana 36 de gestación y hasta el parto. No se observaron diferencias en la proliferación de sus linfocitos CD4, en la respuesta a la estimulación de los linfocitos del recién nacido con ovoalbúmina o hemocianina de lapa (keyhole limpet hemocyanin), en la expresión de ARNm de FoxP3 en las células dendríticas o de factores regulación de los procesos de inflamación (IL10, -12 y -13, IFN-g, TGF-b1 y TNF-a). Este estudio indicaría que los efectos de la administración de Lactobacillus GG a la madre embarazada no se transferirían al feto por la vía transplacentaria (95). Un estudio efectuado en Alemania demostró que Lactobacillus GG no ejercería afectos sobre la dermatitis atópica o el asma y sólo tuvo efectos estimados leves sobre los marcadores de sensibilización alérgica, los que persistieron por 6 meses después de suspender el probiótico (96). Aunque a los 2 años se mantenían las mejorías de los fenómenos de sensibilización, cuatro años después no se detectaban efectos sobre los síntomas respiratorios (97). Szajewska y colaboradores no detectaron efectos positivos de Lactobacillus GG en lactantes que experimentaban episodios de sangrado rectal durante la lactancia aunque la madre restringía el consumo de productos lácteos durante dicho período y creen que este probiótico no debería ser empleado en el tratamiento de este cuadro (98).

Es difícil encontrar una explicación para las diferencias entre los resultados al comparar las diversas investigaciones. Es evidente que en el efecto de los probióticos intervienen factores dependientes de la bacteria misma, incluyendo su viabilidad y estado fisiológico, la matriz o el vehículo en que son administradas, la dosis, y su frecuencia así como la duración de su administración. Por otro lado, quien recibe el probiótico, sea madre embarazada, lactante o adulto, interactúa con el agente a través de mecanismos que discriminan a los probióticos de los miembros de la microbiota residente y de los patógenos potenciales. En este proceso participan otros factores propios del individuo: su genética, historia de salud y enfermedad, la maduración funcional de sus sistemas defensivos, su historia nutricional y factores individuales que regulan la calidad de sus respuestas inmunes y cuyo papel es difícil de evaluar. Respecto del efecto de los probióticos hay factores que todavía son poco conocidos. El tubo digestivo mismo, con sus múltiples factores defensivos dispuestos escalonadamente, es un sistema cuya complejidad no se conoce en su totalidad. Con todo, existe irrefutablemente el precedente de que diversas bacterias han sido utilizadas por muchos años en la alimentación y la medicina tradicional y cuyas propiedades son aprovechadas en la actualidad por la ciencia médica y que la población estima positivas; los alimentos y las bacterias que contienen son expendidos sin control estricto y sin que se conozca en todo su detalle cuales son sus mecanismos de acción. Lo que es más importante, pese a su consumo masivo no se han detectado efectos negativos de parte de estas bacterias que alarmen a la comunidad científica.

Lactobacillus GG y cuadros funcionales gastrointestinales. De acuerdo con los criterios de Roma III, los cuadros gastrointestinales relacionados con el dolor abdominal que afectan a los niños pueden ser categorizados como dispepsia funcional, síndrome del intestino irritable, migraña abdominal y dolor abdominal funcional. La fisiopatología de estas manifestaciones no se conoce en todo su detalle y por este motivo hay considerable interés por explorar opciones novedosas de tratamiento, entre ellas el empleo de probióticos (99).

Uno de los primeros ensayos del efecto del LactobacillusGG en relación con el síndrome del intestino irritable en niños fue realizado por Bausserman y Michail (100). Compararon el efecto de este lactobacilo y un placebo administrados por 6 semanas a niños con dolor abdominal recurrente sin encontrar que el probiótico fuera superior. En cambio, dos publicaciones posteriores, a las que se suman comentarios y un meta-análisis, respaldan el concepto de que Lactobacillus GG ejerce efectos positivos sobre las manifestaciones descritas en Roma III (101-105).

Los mecanismos por los cuales Lactobacillus GG ejerce sus afectos en estos cuadros no se conocen en su integridad pero es posible que sean similares a aquellos a través de los cuales L. reuteri ejerce sus efectos sobre el cólico de los lactantes, es decir, a través de bloqueos de la transmisión de impulsos dolorosos a nivel de los ganglios dorsales de la médula espinal y a nivel de núcleos centrales del ssitema nervioso central de donde parten señales eferentes hacia los órganos abdominales (106-110). Este es un campo que ha comenzado a ser explorado recientemente y probablemente alcanzará proyecciones no imaginadas hasta ahora acerca de las relaciones entre la microbiota residente y el cerebro.

\section{RESUMEN}

Los lactobacilos son habitantes normales de las mucosas de los seres humanos; también están presentes en la leche materna. Lactobacillus reuteri fue descrito en la leche de una madre peruana, lo que confirma que estas bacterias son parte de la microbiota que las madres transfieren a sus hijos. El cólico infantil son episodios de llanto excesivo, estridente, por a lo menos 3 horas 3 veces por semana y por a lo menos 3 meses. L. reuteri ATCC 55730 demostró disminuir su intensidad y duración. La etiología del cólico se desconoce pero en las heces de los lactantes afectados se han demostrado disminuciones de los lactobacilos y aumentos de Bacteroides. En 2008 se demostró que L. reuteri ATCC 55730 era portador de plasmidios capaces de resistencia a antibióticos por lo que fue "curado" de estos factores y resultó una nueva cepa, denominada DSM 17938; pruebas in vitro y en animales mostraron su inocuidad y ensayos en humanos revelaron que ejerce las mismas propiedades benéficas que la cepa original. El efecto de L. reuteri en el cólico infantil puede estar relacionado con su capacidad de bloquear en los ganglios dorsales de la medula espinal la transmisión de estímulos a los centros cerebrales superiores. El efecto antirreflujo de L. reuteri se debería a la aceleración del vaciamiento gástrico. Ambas cepas de esta bacteria disminuyen la progresión, morbilidad y mortalidad de la enterocolitis necrosante. Otros efectos en la constipación crónica y la duración de la diarrea aguda de distintas etiologías. L. reuteri sintetiza una molécula, el $\beta$-hidroxipropenal o reuterina, con actividad antibacteriana. Lactobacillus rhamnosus GG ATCC 53103 es probablemente el probiótico más estudiado; acorta la duración de la diarrea aguda, disminuye el número de evacuaciones y la duración de los vómitos e induce mejorías de la diarrea asociada con los tratamientos antibióticos; y disminuiría la intensidad de las infecciones respiratorias altas. Sus efectos se deberían a la estimulación de las inmunidades innata y adquirida y de la activación de los macrófagos y los linfocitos NK. Un efecto notable y discutido de L. ramnosus GG se refiere a sus efectos en la atopia cutánea, ya que disminuiría la extensión e intensidad de sus síntomas, incluso más allá de su administración. También ejercería efectos sobre cuadros 
funcionales gastrointestinales como el síndrome del intestino irritable, por mecanismos aun no elucidados.

Palabras clave: Lactobacillus reuteri ATCC 53730; Lactobacillus reuteri DSM 17938; Lactobacillus rhamnosus GG ATCC 53103; reuterina, diarrea aguda.

\section{BIBLIOGRAFÍA}

1. Kandler $O$, Stetter $K, K o h I R$. Lactobacillus reuteri sp.nov a new species of heterofermentative lactobacilli. Zbl Bakt Hyg Abt Orig 1980; C1: 264-9.

2. Wessel MA, Cobb JC, Jackson EB, Harris GS, Detwiler AC. Paroxismal fussing in infancy, sometimes called "colic". Pediatrics 1954; 14: 421-35.

3. Kirjavainen J, Kirjavainen $T$, Huhtala $V$, Lehtonen $L$, Korvenranta $H$, Kero $P$. J Infants with colic have a normal sleep structure at 2 and 7 months of age. Pediatr 2001; 138: 218-23.

4. Hide DW, Guyer BM. Prevalence of infant colic. Arch Dis Child. 1982; 57: 559-60.

5. Savino F, Cresi F, Pautasso S, Palumeri E, Tullio V, Roana J, Silvestro L, Oggero R. Intestinal microflora in breastfed colicky and non-colicky infants. Acta Paediatr. 2004; 93 : 825-29.

6. Savino F, Pelle E, Palumeri E, Oggero R, Miniero R. Lactobacillus reuteri (American Type Culture Collection Strain 55730) versus simethicone in the treatment of infantile colic: a prospective randomized study. Pediatrics 2007; 119: $124-30$

7. Rosander A, Connolly E, Roos S. Removal of antibiotic resistance gene-carrying plasmids from Lactobacillus reuteri ATCC 55730 and characterization of the resulting daughter strain, L. reuteri DSM 17938. Appl Environ Microbiol. 2008; 74: 6032-40.

8. Savino $F$, Cordisco $L$, Tarasco $V$, Palumeri $E$, Calabrese $R$, Oggero $R$, Roos S, Matteuzzi D. Lactobacillus reuteri DSM 17938 in infantile colic: a randomized, double-blind, placebo-controlled trial. Pediatrics 2010; 126: e526-33.

9. Szajewska H, Gyrczuk E, Horvath A. Lactobacillus reuteri DSM 17938 for the management of infantile colic in breastfed Infants: a randomized, double-blind, placebo-controlled trial. J Pediatr 2012. pii: S0022-3476(12)00920-1.

10. Rousseaux C, Thuru X, Gelot A, Barnich N, Neut C, Dubuquoy L, Dubuquoy C, Merour E, Geboes K, Chamaillard $M$, Ouwehand A, Leyer G, Carcano D, Colombel JF, Ardid $D$, Desreumaux P. Lactobacillus acidophilus modulates intestinal pain and induces opioid and cannabinoid receptors. Nat Med. 2007; 13: 35-7.

11. Kunze WA, Mao YK, Wang $B$, Huizinga JD, Ma X, Forsythe $P$, Bienenstock J. Lactobacillus reuteri enhances excitability of colonic $\mathrm{AH}$ neurons by inhibiting calcium-dependent potassium channel opening. J Cell Mol Med. 2009; 13: 2261-70.

12. Wang $B$, Mao $Y K$, Diorio $C$, Wang $L$, Huizinga JD, Bienenstock J, Kunze W. Lactobacillus reuteri ingestion and IK(Ca) channel blockade have similar effects on rat colon motility and myenteric neurones. Neurogastroenterol Motil 2010; 22: 98-107.

13. Ma X, Mao YK, Wang B, Huizinga JD, Bienenstock J, Kunze $W$. Lactobacillus reuteri ingestion prevents hyperexcitability of colonic DRG neurons induced by noxious stimuli. Am J Physiol Gastrointest Liver Physiol. 2009; 296: G868-75.

14. Bercik P, Park AJ, Sinclair D, Khoshdel A, Lu J, Huang $X$, Deng $Y$, Blennerhassett PA, Fahnestock M, Moine D, Berger $B$, Huizinga JD, Kunze W, McLean PG, Bergonzelli
GE, Collins SM, Verdu EF. The anxiolytic effect of Bifidobacterium longum NCC3001 involves vagal pathways for gut-brain communication. Neurogastroenterol Motil 2011; 23: 1132-9.

15. Indrio F, Riezzo G, Raimondi F, Bisceglia M, Cavallo L, Francavilla $R$. The effects of probiotics on feeding tolerance, bowel habits and gastrointestinal motility in premature newborns. J Pediatr. 2008; 152: 801-06.

16. Hunter, C, Dimaguila MAT, Gal P, Wimmer JE, Ransom $J L$, Carlos RQ, Smith MCC, Davanzo C. Effect of routine probiotic, Lactobacillus reuteri DSM 17938, use on rates of necrotizing enterocolitis in neonates with birthweight <1000 grams: a sequential study. BMC Pediatrics 2012; 12: 142-7.

17. Coccurullo P, Strisciuglio C, Martinelli M, Miele M, Greco L, Staiano A. Lactobacillus reuteri DSM 17938) in infants with functional chronic constipation: a doule-blind, randomized, placebo controlled study. J Pediatr. 2010; 157: 598-602.

18. Romano $C$, Ferrau $V$, Cavataio $F$, lacono $G$, Spina M, Lionetti $E$, Comisi F, Famiani A, Comito D. Lactobacillus reuteri in children with functional abdominal pain (FAP). J Paediatr Child Health. $2010 \mathrm{Jul}$ 8. [Epub ahead of print]

19. Storr MA, Yüce $B$, Andrews CN, Sharkey KA. The role of the endocannabinoid system in the pathophysiology and treatment of irritable bowel syndrome. Neurogastroenterol Motil. 2008; 20: 857-68.

20. Wanke M, Szajewska H. Lack of an effect of Lactobacillus reuteri DSM 17938 in preventing nosocomial diarrhea in children: a randomized, double-blind, placebo-controlled trial. J Pediatr. 2012; 161: 40-3.

21. Savino F, Cordisco L, Tarasco V, Calabrese $R$, Palumeri $E$, Matteuzzi D. Molecular identification of coliform bacteria from colicky breastfed infants. Acta Paediatr. 2009; 98: 1582-8.

22. Saavedra JM, Bauman NA, Oung I, Perman JA, Yolken RH. Feeding of Bifidobacterium bifidum and Streptococcus thermophilus to infants in hospital for prevention of diarrhoea and shedding of rotavirus. Lancet 1994; 344: 1046-9.

23. Francavilla $R$, Lionetti $E$, Castellaneta $S$, Ciruzzi $F$, Indrio $F$, Masciale A, Fontana C, La Rosa MM, Cavallo L, Francavilla A. Randomised clinical trial: Lactobacillus reuteri DSM 17938 vs. placebo in children with acute diarrhoea--a double-blind study. Aliment Pharmacol Ther. 2012; 36: 363-9.

24. Shornikova AV, Casas IA, Isolauri E, Mykkänen H, Vesikari T. Lactobacillus reuteri as a therapeutic agent in acute diarrhea in young children. J Pediatr Gastroenterol Nutr 1997: 24: 399-404.

25. Talarico TL, Casas IA, Chung TC, Dobrogosz WJ. Production and isolation of reuterin, a growth inhibitor produced by Lactobacillus reuteri. Antimicrob Agents Chemother. 1988 Dec;32(12):1854-8.

26. Francavilla $R$, Lionetti $E$, Castellaneta $S P$, Magistà $A M$, Maurogiovanni G, Bucci N, De Canio A, Indrio F, Cavallo $L$, lerardi E, Miniello VL. Inhibition of Helicobacter pylori infection in humans by Lactobacillus reuteri ATCC 55730 and effect on eradication therapy: a pilot study. Helicobacter 2008; 13: 127-34.

27. Branton $W B$, Jones $M L$, Tomaro-Duchesneau C, Martoni CJ, Prakash S. In vitro characterization and safety of the probiotic strain Lactobacillus reuteri Cardioviva NCIMB 30242, Int J Probiotics Prebiotics 2011: 6: 1-12.

28. Jones ML, Martoni CJ, Parent M, Prakash S. Cholesterol- 
lowering efficacy of a microencapsulated bile salt hydrolase-active Lactobacillus reuteri NCIMB 30242 yoghurt formulation in hypercholesterolaemic adults $\mathrm{Br} J$ Nutr. 2012; 107: 1505-13.

29. Jones ML, Martoni CJ, Tamber S, Parent M, Prakash. Evaluation of safety and tolerance of microencapsulated Lactibacillus reuteri NCIMB 30242 in a yogourt formulation: a randomized, placebo controlled, double-blind study. Food Chem Toxicol. 2012: 50: 2216-23.

30. Jones ML, Martoni CJ, Di Pietro E, Simon RR, Prakash S. Evaluation of clinical safety and tolerance of a Lactobacillus reuteri NCIMB 30242 supplement capsule: a randomized control trial. Regul Toxicol Pharmacol. 2012; 63:313-20.

31. Jones ML, Martoni CJ, Prakash S. Cholesterol lowering and inhibition of sterol absorption by Lactobacillus reuteri NCIMB 30242: a randomized controlled trial. Eur J Clin Nutr. 2012; 66: 1234-41.

32. Shornikova AV, Casas IA, Mykkänen H, Salo E, Vesikari T. Bacteriotherapy with Lactobacillus reuteri in rotavirus gastroenteritis. Pediatr Infect Dis J. 1997;16:1103-7.

33. Weizman Z, Asli G, Alsheikh A. Effect of a probiotic infant formula on infections in child care centers: comparison of two probiotic agents. Pediatrics 2005; 115: 5-9.

34. de Vrese M, Marteau PR. Probiotics and prebiotics: effects on diarrhea. J Nutr 2007; 137(3 Suppl 2): 803S-11S.

35. Francavilla $R$, Lionetti $E$, Castellaneta S, Ciruzzi F, Indrio $F$, Masciale A, Fontana C, La Rosa MM, Cavallo L, Francavilla A. Randomised clinical trial: Lactobacillus reuteri DSM 17938 vs. placebo in children with acute diarrhoea--a double-blind study. Aliment Pharmacol Ther. 2012; 36: 363-9.

36. Agustina $R$, Kok FJ, van de Rest O, Fahmida U, Firmansyah A, Lukito W, Feskens EJ, van den Heuvel EG, Albers $R$, Bovee-Oudenhoven IM. Randomized trial of probiotics and calcium on diarrhea and respiratory tract infections in Indonesian children. Pediatrics 2012; 129:e1155-64.

37. Ojetti V, Bruno $G$, Ainora ME, Gigante $G$, Rizzo G, Roccarina D, Gasbarrini A. Impact of Lactobacillus reuteri supplementation on anti-Helicobacter pylori levofloxacinbased second-line therapy. Gastroenterol Res Pract. 2012;2012:740381.

38. Szajewska H, Wanke M, Patro B. Meta-analysis: the effects of Lactobacillus rhamnosus GG supplementation for the prevention of healthcare-associated diarrhoea in children. Aliment Pharmacol Ther. 2011; 34: 1079-87.

39. Rosenfeldt $V$, Michaelsen $K F$, Jakobsen $M$, Larsen $C N$, Møller PL, Pedersen P, Tvede M, Weyrehter $H$, Valerius NH, Paerregaard A. Effect of probiotic Lactobacillus strains in young children hospitalized with acute diarrhea. Pediatr Infect Dis J. 2002; 21: 411-6.

40. Silva M, Jacobus NV, Deneke C, Gorbach SL. Antimicrobial substance from a human Lactobacillus strain. Antimicrob Agents Chemother. 1987; 31: 1231-1233.

41. Goldin BR, Gorbach SL, Saxelin M, Barakat S, Gualtieri L, Salminen S. Survival of Lactobacillus species (strain GG) in human gastrointestinal tract. Dig Dis Sci 1992; 37: 121-8.

42. Alander $M$, Satokari $R$, Korpela $R$, Saxelin M, VilpponenSalmela $T$, Mattila-Sandholm T, von Wright A. Persistence of colonization of human colonic mucosa by a probiotic strain, Lactobacillus rhamnosus GG, after oral consumption. Appl Environ Microbiol. 1999; 65: 351-4.

43. Petschow BW, Figueroa $R$, Harris $C L$, Beck $L B$, Ziegler $E$, Goldin B. Effects of feeding an infant formula containing Lactobacillus GG on the colonization of the intestine: $a$ dose-response study in healthy infants. J Clin Gastroenterol. 2005; 39: 786-90.

44. Dommels YE, Kemperman RA, Zebregs YE, Draaisma RB, Jol A, Wolvers DA, Vaughan EE, Albers $R$. Survival of Lactobacillus reuteri DSM 17938 and Lactobacillus rhamnosus GG in the human gastrointestinal tract with daily consumption of a low-fat probiotic spread. Appl Environ Microbiol. 2009; 75: 6198-204.

45. Majamaa $H$, Isolauri E, Saxelin M, Vesikari T. Lactic acid bacteria in the treatment of acute rotavirus gastroenteritis. J Pediatr Gastroenterol Nutr.1995; 20: 333-38.

46. Shornikova AV, Isolauri E, Burkanova L, Lukovnikova S, Vesikari T. A trial in the Karelian Republic of oral rehydration and Lactobacillus GG for treatment of acute diarrhoea. Acta Paediatr. 1997; 86: 460-5.

47. De Keersmaecker SC, Verhoeven TL, Desair J, Marchal $K$, Vanderleyden J, Nagy I. Strong antimicrobial activity of Lactobacillus rhamnosus GG against Salmonella typhimurium is due to accumulation of lactic acid. FEMS Microbiol Lett. 2006; 259:89-96.

48. Szajewska H, Skórka A, Ruszczyński M, Gieruszczak-Białek D. Meta-analysis: Lactobacillus GG for treating acute diarrhoea in children. Aliment Pharmacol Ther. 2007; 25: 871-81.

49. Berni Canani $R$, Cirillo $P$, Terrin $G$, Cesarano L, Spagnuolo MI, De Vincenzo A, Albano F, Passariello A, De Marco G, Manguso F, Guarino A. Probiotics for treatment of acute diarrhoea in children: randomised clinical trial of five different preparations. BMJ 2007; 335: 40.

50. Szymański H, Pejcz J, Jawień M, Chmielarczyk A, Strus $M$, Heczko PB. Treatment of acute infectious diarrhoea in infants and children with a mixture of three Lactobacillus rhamnosus strains - a randomized, double-blind, placebo-controlled trial. Aliment Pharmacol Ther. 2006; 23: 247-53.

51. de Vrese M, Marteau PR. Probiotics and prebiotics: effects on diarrhea. J Nutr. 2007; 137(3 Supp/ 2): 803S-11S.

52. Pieścik-Lech M, Urbańska M, Szajewska H. Lactobacillus GG (LGG) and smectite versus LGG alone for acute gastroenteritis: a double-blind, randomized controlled trial. Eur J Pediatr. 2012 Nov 1. [Epub ahead of print]

53. Misra S, Sabui TK, Pal NK. A randomized controlled trial to evaluate the efficacy of Lactobacillus GG in infantile diarrhea. J Pediatr. 2009; 155: 129-32.

54. Ferrie S, Daley M. Lactobacillus GG as treatment for diarrhea during enteral feeding in critical illness: randomized controlled trial. JPEN J Parenter Enteral Nutr. 2011; 35: 43-9.

55. Ritchie $B K$, Brewster DR, Tran CD, Davidson GP, McNeil $Y$, Butler RN. Efficacy of Lactobacillus GG in aboriginal children with acute diarrhoeal disease: a randomised clinical trial. J Pediatr Gastroenterol Nutr. 2010; 50: 619-24.

56. Salazar-Lindo $E$, Miranda-Langschwager P, Campos-Sanchez M, Chea-Woo E, Sack RB. Lactobacillus casei strain GG in the treatment of infants with acute watery diarrhea: a randomized, double-blind, placebo controlled clinical trial [ISRCTN67363048]. BMC Pediatr. 2004 2;4-18.

57. Guandalini S. Probiotics for children with diarrhea: an update. J Clin Gastroenterol. 2008; 42 Suppl 2: S53-7.

58. Pieścik-Lech M, Urbańska M, Szajewska H. Lactobacillus GG (LGG) and smectite versus LGG alone for acute gastroenteritis: a double- blind, randomized controlled trial. Eur J Pediatr. 2012 Nov 1 [Epub ahead of print].

59. Arvola T, Laiho K, Torkkeli S, Mykkänen H, Salminen 
S, Maunula L, Isolauri E. Prophylactic Lactobacillus GG reduces antibiotic-associated diarrhea in children with respiratory infections: a randomized study. Pediatrics 1999 Nov;104(5):e64.

60. Ellison RT 3rd. Review: probiotics are effective for prevention of antibiotic-associated diarrhea and treatment of Clostridium difficile disease. ACP J Club 2006; 145: 46.

61. McFarland LV. Meta-analysis of probiotics for the prevention of antibiotic associated diarrhea and the treatment of Clostridium difficile disease. Am J Gastroenterol. 2006; 101: 812-22.

62. Floch $M H$, Walker WA, Guandalini S, Hibberd P, Gorbach S, Surawicz C, Sanders ME, Garcia-Tsao G, Quigley EM, Isolauri E, Fedorak RN, Dieleman LA. Recommendations for probiotic use: 2008. J Clin Gastroenterol. 2008; 42 Suppl 2: S104-8.

63. Louhiala PJ, Jaakkola N, Ruotsalainen R, Jaakkola JJ. Form of day care and respiratory infections among Finnish children. Am J Public Health. 1995; 85 (8 Pt 1): 1109-12.

64. Hatakka K, Savilahti E, Pönkä A, Meurman JH, Poussa T, Näse L, Saxelin M, Korpela R. Effect of long term consumption of probiotic milk on infections in children attending day care centres: double blind, randomised trial. BMJ 2001; 322: 1327.

65. Hojsak I, Snovak N, Abdović S, Szajewska H, Misak Z, Kolacek S. Lactobacillus GG in the prevention of gastrointestinal and respiratory tract infections in children who attend day care centers: a randomized, double-blind, placebo-controlled trial. Clin Nutr. 2010; 29: 312-16.

66. Hojsak I, Abdović S, Szajewska H, Milosević M, Krznarić Z, Kolacek S. Lactobacillus GG in the prevention of nosocomial gastrointestinal and respiratory tract infections. Pediatrics 2010; 125: e1171-7.

67. Kumpu M, Kekkonen RA, Kautiainen $H$, Järvenpää $S$, Kristo A, Huovinen P, Pitkäranta A, Korpela R, Hatakka K. Milk containing probiotic Lactobacillus rhamnosus GC and respiratory illness in children: a randomized, doubleblind, placebo-controlled trial. Eur J Clin Nutr. 2012; 66: 1020-23.

68. Bunselmeyer B, Butddendick K. Probiotics and prebiotics Prevention and therapy in atopic eczema. En: DR Watson, VR Preedy, editors. Bioactive foods in promoting health: probiotics and prebiotics. $1^{a}$ edición. San Diego: Academic Press, Inc. 2010; 279-92.

69. Yan F, Cao H, Cover TL, Washington MK, Shi Y, Liu L, Chaturvedi R, Peek RM Jr, Wilson KT, Polk DB. Colonspecific delivery of a probiotic-derived soluble protein ameliorates intestinal inflammation in mice through an EGFR-dependent mechanism. J Clin Invest. 2011; 121: 2242-53.

70. Aberg N, Hesselmar B, Aberg B, Eriksson B. Increase of asthma, allergic rhinitis and eczema in Swedish schoolchildren between 1979 and 1991. Clin Exp Allergy. 1995; 25: 815-9.

71. Ninan TK, Russell G. The changing picture of childhood asthma. Paediatr Respir Rev. 2000; 1: 71-78.

72. Otters $H B$, van der Wouden JC, Schellevis FG, van Suijlekom-Smit LW, Koes BW. Changing morbidity patterns in children in Dutch general practice: 1987-2001. Eur J Gen Pract. 2005; 11: 17-22.

73. Sicherer SH, Muñoz-Furlong A, Godbold JH, Sampson HA. US prevalence of self-reported peanut, tree nut, and sesame allergy: 11-year follow-up. J Allergy Clin Immunol. 2010; 125: $1322-26$.
74. Toh ZQ, Anzela A, Tang ML, Licciardi PV. Probiotic therapy as a novel approach for allergic disease. Front Pharmacol. 2012; 3:171. Epub 2012 Sep 21.

75. Zuidmeer L, Goldhahn K, Rona RJ, Gislason D, Madsen C, Summers C, Sodergren E, Dahlstrom J, Lindner T, Sigurdardottir ST, McBride D, Keil T. The prevalence of plant food allergies: a systematic review. J Allergy Clin Immunol. 2008; 121: 1210-18.18.

76. Rona RJ, Keil T, Summers C, Gislason D, Zuidmeer L, Sodergren E, Sigurdardottir ST, Lindner T, Goldhahn K, Dahlstrom J, McBride D, Madsen C. The prevalence of food allergy: a meta-analysis. J Allergy Clin Immunol. 2007; 120: 638-46.

77. Kalliomäki M, Salminen S, Arvilommi H, Kero P, Koskinen $P$, Isolauri E. Probiotics in primary prevention of atopic disease: a randomised placebo-controlled trial. Lancet 2001; 357: 1076-9.

78. Kalliomäki M, Salminen S, Poussa T, Arvilommi H, Isolauri E. Probiotics and prevention of atopic disease: 4-year follow-up of a randomised placebo-controlled trial. Lancet 2003; 361: 1869-71.

79. Kalliomäki M, Salminen S, Poussa T, Isolauri E. Probiotics during the first 7 years of life: a cumulative risk reduction of eczema in a randomized, placebo-controlled trial. I Allergy Clin Immunol. 2007; 119: 1019-21.

80. Kirjavainen PV, Salminen SJ, Isolauri E. Probiotic bacteria in the management of atopic disease: underscoring the importance of viability. J Pediatr Gastroenterol Nutr. 2003; 36: 223-27.

81. Pohjavuori $E$, Viljanen $M$, Korpela $R$, Kuitunen $M$, Tiittanen $M$, Vaarala $O$, Savilahti E. Lactobacillus GG effect in increasing IFN-gamma production in infants with cow's milk allergy. J Allergy Clin Immunol. 2004; 114: 131-6.

82. Viljanen $M$, Kuitunen M, Haahtela T, Juntunen-Backman $K$, Korpela $R$, Savilahti $E$. Probiotic effects on faecal inflammatory markers and on faecal IgA in food allergic atopic eczema/dermatitis syndrome infants. Pediatr Allergy Immunol. 2005; 16: 65-71.

83. Bischoff S, Crowe SE. Food allergy and the gastrointestinal tract. Curr Opin Gastroenterol. 2004; 20: 156-61.

84. Viljanen M, Pohjavuori E, Haahtela T, Korpela R, Kuitunen M, Sarnesto A, Vaarala $O$, Savilahti E. Induction of inflammation as a possible mechanism of probiotic effect in atopic eczema-dermatitis syndrome. J Allergy Clin Immunol. 2005; 115: 1254-9.

85. Viljanen $M$, Savilahti E, Haahtela T, Juntunen-Backman $K$, Korpela R, Poussa T, Tuure T, Kuitunen M. Probiotics in the treatment of atopic eczema/dermatitis syndrome in infants: a double-blind placebo-controlled trial. Allergy 2005; 60: 494-500.

86. Baldassarre ME, Laforgia N, Fanelli M, Laneve A, Grosso R, Lifschitz C. Lactobacillus GG improves recovery in infants with blood in the stools and presumptive allergic colitis compared with extensively hydrolyzed formula alone. J Pediatr. 2010; 156: 397-401.

87. Berni Canani $R$, Nocerino $R$, Terrin $G$, Coruzzo A, Cosenza $L$, Leone $L$, Troncone R. Effect of Lactobacillus GG on tolerance acquisition in infants with cow's milk allergy: a randomized trial. J Allergy Clin Immunol. 2012; 129: 580-2.

88. Mileti E, Matteoli G, Iliev ID, Rescigno M. Comparison of the immunomodulatory properties of three probiotic strains of Lactobacilli using complex culture systems: prediction for in vivo efficacy. PLoS One 2009:16;4 (9):e7056.

89. Muraro A, Hoekstra MO, Meijer Y, Lifschitz C, Wampler $J L$, Harris C, Scalabrin DM. Extensively hydrolysed casein 
formula supplemented with Lactobacillus rhamnosus GG maintains hypoallergenic status: randomised double-blind, placebo-controlled crossover trial. BMJ Open. 2012; 2: e000637.

90. Kawase M, He F, Kubota A, Hiramatsu M, Saito H, Ishii T, Yasueda $H$, Akiyama K. Effect of fermented milk prepared with two probiotic strains on Japanese cedar pollinosis in a double-blind placebo-controlled clinical study. Int J Food Microbiol. 2009; 128: 429-34.

91. Kubota A, He F, Kawase M, Harata $G$, Hiramatsu M, lino $H$. Diversity of intestinal bifidobacteria in patients with Japanese cedar pollinosis and possible influence of probiotic intervention. Curr Microbiol. 2011; 62: 71-7.

92. Brouwer $M L$, Wolt-Plompen SA, Dubois AE, van der Heide $S$, Jansen DF, Hoijer MA, Kauffman HF, Duiverman EJ. No effects of probiotics on atopic dermatitis in infancy: a randomized placebo-controlled trial. Clin Exp Allergy. 2006; 36: 899-906.

93. Kopp MV, Hennemuth I, Heinzmann A, Urbanek R. Randomized, double-blind, placebo-controlled trial of probiotics for primary prevention: no clinical effects of Lactobacillus GG supplementation. Pediatrics 2008; 121: e850-56.

94. Boyle RJ, Mah LJ, Chen A, Kivivuori S, Robins-Browne RM, Tang ML. Effects of Lactobacillus GG treatment during pregnancy on the development of fetal antigen-specific immune responses. Clin Exp Allergy. 2008; 38: 1882-90.

95. Rose MA, Stieglitz F, Köksal A, Schubert R, Schulze J, Zielen S. Efficacy of probiotic Lactobacillus GG on allergic sensitization and asthma in infants at risk. Clin Exp Allergy. 2010; 40: 1398-405.

96. Rose MA, Schubert $R$, Schulze J, Zielen S. Follow-up of probiotic Lactobacillus GG effects on allergic sensitization and asthma in infants at risk. Clin Exp Allergy. 2011; 41: 1819-21.

97. Szajewska H, Gawronska A, Wos $H$, Banaszkiewicz A, Grzybowska-Chlebowczyk U. Lack of effect of Lactobacillus GG in breast-fed infants with rectal bleeding: a pilot double-blind randomized controlled trial. J Pediatr Gastroenterol Nutr. 2007; 45: 247-51.

98. Hyman PE, Milla PJ, Benninga MA, Davidson GP, Fleisher $D F$, Taminiau J. Childhood functional gastrointestinal disorders: neonate/toddler. Gastroenterology 2006; 130: 1519-26.
99. Bausserman M, Michail S. The use of Lactobacillus GG in irritable bowel syndrome in children: a double-blind randomized control trial. J Pediatr. 2005; 147: 197-201.

100. Gawrońska A, Dziechciarz P, Horvath A, Szajewska H. $A$ randomized double-blind placebo-controlled trial of Lactobacillus GG for abdominal pain disorders in children. Aliment Pharmacol Ther. 2007; 25: 177-84.

101. Francavilla $R$, Miniello V, Magistà AM, De Canio A, Bucci $N$, Gagliardi F, Lionetti E, Castellaneta S, Polimeno L, Peccarisi L, Indrio F, Cavallo L. A randomized controlled trial of Lactobacillus GG in children with functional abdominal pain. Pediatrics 2010; 126: e1445-52.

102. Abu-Salih M, Dickinson CJ. Lactobacillus GG may improve frequency and severity of pain in children with functional abdominal pain. J Pediatr. 2011; 159: 165-6.

103. Vandenplas Y, Benninga M. Probiotics and functional gastrointestinal disorders in children. J Pediatr Gastroenterol Nutr 2009; 48 Suppl 2: S107-09.

104. Horvath A, Diechciarz P, Szajewska H. Meta-analysis: Lactobacillus rhamnossus GG for abdominal pain-related functional gastrointestinal disorders in childhood. Aliment Pharmacol Ther.2011; 33: 1302-10.

105. Kunze WA, Mao YK, Wang B, Huizinga JD, Ma X, Forsythe $P$, Bienenstock J. Lactobacillus reuteri enhances excitability of colonic $\mathrm{AH}$ neurons by inhibiting calcium-dependent potassium channel opening. I Cell Mol Med. 2009; 13: 2261-70.

106. Wang B, Mao YK, Diorio C, Wang L, Huizinga JD, Bienenstock J, Kunze W. Lactobacillus reuteri ingestion and IK(Ca) channel blockade have similar effects on rat colon motility and myenteric neurones. Neurogastroenterol Motil. 2010; 22: 98-107.

107. Ma X, Mao YK, Wang B, Huizinga JD, Bienenstock J, Kunze $W$. Lactobacillus reuteri ingestion prevents hyperexcitability of colonic DRG neurons induced by noxious stimuli. Am J Physiol Gastrointest Liver Physiol. 2009; 296: G868-75.

108. Bercik P, Park AJ, Sinclair D, Khoshdel A, Lu J, Huang $X$, Deng Y, Blennerhassett PA, Fahnestock M, Moine D, Berger $B$, Huizinga JD, Kunze W, McLean PG, Bergonzelli GE, Collins SM, Verdu EF. The anxiolytic effect of Bifidobacterium longum NCC3001 involves vagal pathways for gut-brain communication. Neurogastroenterol Motil. 2011; 23: 1132-9. 